УДК $78.05+78.07$

Наталия Алексеевна Селезнёва

доцент кафедры теории музыки и композиции

Одесской национальной музыкальной академии имени А. В. Неждановой natali.selezneva25@gmail.com

\title{
К ПРОБЛЕМЕ ОСВОЕНИЯ ЯЗЫКА СОВРЕМЕННОЙ МУЗЫКИ В КУРСЕ ЧТЕНИЯ ХОРОВЫХ ПАРТИТУР (НА ПРИМЕРЕ ЦИКЛА «ШЕСТЬ ПЕСЕН» П. ХИНДЕМИТА)
}

Цель исследования - привлечь внимание преподавателей и студентов к выдающимся художественным достоинствам и образовательному потенциалу хоровой музыки П. Хиндемита, а также представить некоторые учебно-методические соображкения, связанные с освоением современного музыкального языка. Методологическую основу исследования образует целостный подход к проблеме освоения студентом музыкального языка современной музыки, в котором, независимо от изучаемой академической дисциплины, пересекаются и дополняют друг друга исторический, теоретический и собственно исполнительский аспекты. Научная новизна заключается в рассмотрении именно с этой точки зрения иикла Пауля Хиндемита «Шесть песен» на тексты оригинальных франиузских поэм Р. Рильке для смешанного хора без сопровождения. Выводы. Гармонический язык данного произведения, обладающий свойствами принципиальной новизны, органично связан с европейскими традициями фольклора, средневековой монодии и ренессансного многоголосия. На примерах пьес хорового цикла показано, ито свойства аккордики в хорах иикла обусловлены: а) опорой на кварто-квинтовые строевые отношения, б) организующим доминированием акустически чистых интервалов, в) принципом свободного сочетания диатонических тонов в созвучиях, образованных мелодическим движением, г) логикой синтетической аккордово-полифонической фактуры, д) принципом волнообразного нагнетания и разряжения уровня диссонансности созвучий. Доказывается методическая иелесообразность использования иикла в курсе чтения хоровых партитур.

Ключевые слова: гармонический язык, фактура, аккордика, мелодическое движение.

Selezneva Nataliya, associate professor of the department of music theory and composition Odessa A. V. Nezhdanova national academy of music

To the issue of modern music language development in the course of choral score reading (by the example of the cycle of «Six songs» by Hindemith)

Research objective is drawing attention of teachers and students to outstanding art advantages and educational potential of choral music of P. Hindemith

(C) Селезнёва Н. А., 2017 
and also to present some educational and methodical reasons connected with development of modern musical language. The methodological basis of a research is formed by complete approach to a problem of development by the student of musical language of modern music in which, irrespective of the studied academic discipline, are crossed and historical, theoretical and actually performing aspects supplement each other. The scientific novelty consists in consideration from this point of view of a cycle of Paul Hindemith «Six songs» on texts of original French poems of $R$. Rilke for the mixed chorus without accompaniment. Conclusions. The harmonious language of this work having properties of basic novelty is organically connected with the European traditions of folklore, a medieval monody and the Renaissance polyphony. On examples of plays of a choral cycle it is shown that properties of an chords in choruses of a cycle are caused: a) a support on the fourth - fifth front relations, b) organizing domination of acoustically clean intervals, $c$ ) the principle of a free combination of diatonic tones in the chords formed by the melodic movement, d) logic of the synthetic chords and polyphonic invoice, e) the principle of wavy forcing and discharge of level of a dissonant of chords. The methodical expediency of use of a cycle is proved it is aware of reading choral scores.

Keywords: harmonious language, invoice, chords, melodic movement.

Селезньова Наталія Олексіївна, доцент кафедри теорії музики та композиції Одеської національної музичної академії імені А. В. Нежданової

До проблеми опанування мови сучасної музики у курсі читання хорових партитур (на прикладі циклу «Шість пісень» П. Хіндеміта)

Мета дослідження - привернути увагу викладачів і студентів до видатних художніх якостей $і$ освітнього потенціалу хорової музики П. Хіндеміта, а також представити деякі навчально-методичні міркування, пов'язані з освоєнням сучасної музичної мови. Методологічну основу дослідження утворює иілісний підхід до проблеми освоєння студентом музичної мови сучасної музики, в якому, незалежно від досліджуваної академічної дисципліни, перетинаються і доповнюють один одного історичний, теоретичний $і$ власне виконавський аспекти. Наукова новизна полягає в розгляді саме з цієї точки зору циклу Пауля Хіндеміта «Шість пісень» на тексти оригінальних французьких поем Р. Рільке для змішаного хору без супроводу. Висновки. Гармонійна мова даного твору, що володіє властивостями принципової новизни, органічно пов'язана з європейськими традиціями фольклору, середньовічної монодії та ренесансного багатоголосся. На прикладах п'єс хорового циклу показано, що властивості акордики в хорах циклу обумовлені: а) опорою на кварто-квінтові стройові відносини, б) організуючим домінуванням акустично чистих інтервалів, в) принципом вільного поєднання діатонічних тонів у співзвуччях, утворених мелодійним рухом, г) логікою синтетичної акордово-поліфонічної фактури, д) принципом хвилеподібного нагнітання і розрядження 
рівня дисонантності співзвуч. Доводиться методична доцільність використання циклу в курсі читання хорових партитур.

Ключові слова: гармонійна мова, фактура, акордика, мелодійний рух.

Актуальность исследования. Одна из основных задач воспитания и обучения специалиста высшей музыкально-исполнительской квалификации - задача всесторонней подготовки к разным видам деятельности, к решению различных творческих и технических задач, к исполнению функций солиста, ансамблиста, концертмейстера, аккомпаниатора, педагога и др.

Сегодня музыканту, даже обладающему самыми яркими способностями и самым высоким уровнем академической подготовки, недостаточно овладеть определенным классическим репертуаром и обрести умение работы с ним. Сама жизнь, сама практика повседневной деятельности обязательно потребует от него расширения круга освоенных навыков, умений и знаний. В том числе обязательно потребуется владение средствами современного музыкального языка, понимание этих средств, а также умение самостоятельно осваивать новые средства музыкальной выразительности, которые постоянно обновляются.

Поэтому в число главных задач подготовки музыканта-исполнителя высшей квалификации непременно должна включаться задача освоения современного музыкального языка. Данная задача имеет, по всей видимости, комплексный характер. Сама постановка такой задачи, методология и методика ее решения составляют отдельную и сложную музыкально-педагогическую проблему. Ясно и то, что свой вклад в решение этой комплексной задачи могут и должны вносить все дисциплины специального цикла, как историко-теоретические (история современной музыки, гармония, полифония, анализ музыкальных произведений и др.), так и практические (основной инструмент, вокал, хоровой класс и т. д.).

Наименее эффективным способом решения данной задачи было бы формальное разделение ее на отдельные аспекты и разграничение функций отдельных учебных дисциплин в соответствии с формальными критериями. Оптимальным же представляется другой методологический путь, а именно - целостный подход к проблеме освоения студентом музыкального языка современной музыки, в котором, независимо от изучаемой академической дисциплины, пересекаются и дополняют друг друга исторический, теоретический и собственно исполнительский аспекты. С наибольшей очевидностью такой педа- 
гогический подход обнаруживает свои позитивные стороны при изучении какого-то конкретного произведения.

Научная новизна заключается в рассмотрении именно с этой точки зрения цикла Пауля Хиндемита «Шесть песен» на тексты оригинальных французских поэм Р. Рильке для смешанного хора без сопровождения.

Цель статьи - привлечь внимание преподавателей и студентов к выдающимся художественным достоинствам и образовательному потенциалу хоровой музыки П. Хиндемита, а также представить некоторые учебно-методические соображения, связанные с освоением современного музыкального языка.

Объект исследования - цикл П. Хиндемита «Шесть песен» как репрезентант современного языка хоровой музыки.

Изложение основного материала. Композитор родился в XIX веке (1895 г.), но его творческая деятельность относится преимущественно к первой половине XX века, то есть ко времени появления целого «букета» модернистских течений в искусстве. Сегодня отношение к модернистским течениям изменилось. Разнообразные (вплоть до противоположности методов и творческих интенций) произведения композиторов-модернистов первой половины XX века (Ч. Айвза, Б. Бартока, А. Берга, А. Веберна, О. Мессиана, Д. Мийо, С. Прокофьева, Ф. Пуленка, М. Равеля, И. Стравинского, П. Хиндемита, А. Шенберга, Д. Шостаковича и др.) воспринимаются и оцениваются как подлинная музыкальная классика.

Такая оценка означает не только факт признания высоких художественных достоинств произведений этих авторов, но и очевидный факт включения их сочинений в репертуарные комплексы музыкального образования. Можно отметить, что произведения композиторов второй половины XX века и начала XXI века тоже включаются в учебный репертуар солистов, ансамблей, академических хоров и оркестров. Чаще всего это музыка представителей национальных школ. Скажем, в программы подготовки хормейстеров в украинских вузах включены сочинения ныне живущих и здравствующих композиторов: В. Губы, Л. Дычко, В. Сильвестрова, М. Скорика, Е. Станковича, К. Цепколенко и др. Это, безусловно, позитивное явление. Однако для самого широкого музыкального образования, осуществляемого музыкальными вузами, школами и училищами, более важным является обращение к классике XX века, поскольку на основе этого музыкального пласта сформировались все оригинальные стили наших 
дней. Без знания и понимания музыкального языка (или точнее языков) прошлого столетия современный музыкант не способен решить многие насущные творческие задачи, выдвигаемые современной практикой.

В ряду композиторов-классиков современной музыки Пауль Хиндемит занимает одно из первых мест, прежде всего как художник высоких устремлений духа, гуманист, хранитель и поборник этических ценностей музыки, выразитель настроений, идей и стремлений нескольких поколений европейской интеллигенции. Историей отмечены его высокие заслуги в развитии жанров оперы, камерной музыки, полифонических жанров (в частности фуги и канона).

В контексте нашей работы важно, прежде всего, то, что П. Хиндемит справедливо почитается как создатель нового оригинального музыкального языка, отвергающего некоторые нормы традиционной грамматики (особенно в сфере ладотональной организации, аккордики и метроритма), но не разрывающего связи с языками предыдущих эпох. Если в начале своего творческого пути композитор тяготел к радикальному обновлению языковой системы, то в период зрелости он как бы «оборачивается назад», всматривается в историческое прошлое музыкального искусства и возвращается к испытанным средствам выразительности, в частности к приемам И. С. Баха, Л. Бетховена, к старинному мелосу немецкой духовной музыки. В связи с этим его язык становится более традиционным, но не теряет новизны и оригинальности.

Оценивая роль и место П. Хиндемита в истории музыки, Т. Левая и О. Леонтьева - авторы самой полной русскоязычной монографической работы о жизни и творчестве композитора - относят его, в согласии с зарубежной музыковедческой наукой, к «четырем китам», на которых держится вся современная музыка. Согласно этой точке зрения, четыре композитора заложили фундамент новой музыки XX века, дали исходные импульсы для ее дальнейшего развития. Это Арнольд Шенберг, Игорь Стравинский, Бела Барток и Пауль Хиндемит. ...Это исторические места, которых никто другой занять не может» $[4,13]$.

Странно, что авторы монографии, вступая в некоторое противоречие со своими же утверждениями, не слишком высоко оценивают идейно-эстетические и художественно-образные новации П. Хиндемита. Вместе с тем они справедливо акцентируют основное достижение композитора - четкое, целостное, рационально выстроенное 
выражение новых закономерностей ладотональной организации музыкальной речи и принципов аккордового письма: «Неоклассицизм Хиндемита имеет «вторичный» характер после Бузони, Стравинского, Прокофьева. Его экспрессионизм не получил самостоятельного развития, его фольклоризм есть лишь немецкая модификация того, что предложено было Бартоком и Стравинским. Хиндемит входит в эту четверку как теоретик и практик нового тонального мышления, как защитник тонального принципа и теоретик нового, расширенного понимания тональности» $[4,14]$.

Отмеченные свойства творчества Хиндемита, в частности - особенности тонального мышления и гармонии - ярко проявляются в его хоровых произведениях. Композитором создано значительное количество произведений для хора. Среди них выделяются крупномасштабные сочинения для хора с оркестром: оратория «Бесконечное» (Das Unaufhцrliche) на текст Г. Бенна (1931); «Реквием» на слова У. Уитмена (1946); кантата «Apparebit repentina dies» («Внезапно настанет день») на текст анонимного средневекового латинского стихотворения (1947); кантата «Ite angeli veloces» («Летите, быстрые ангелы») на текст П. Клоделя (1955). Для хора a capella П. Хиндемитом создано 15 произведений, к числу которых относятся ряд сборников и циклических композиций: «Песни на старинные тексты» (1923), «Песни для хоровых певческих кружков» (1927), «Пять хоров на тексты Б. Брехта» (1930), «Хоровые песни для мальчиков» на текст К. Шнога, «Три хора на старинные анонимные тексты и текст Ф. Ницше» (1939), «Двенадцать мадригалов» на текст Й. Вайнхебера (1959), Месса на канонический латинский текст ординария (1963).

«Шесть песен» («6 chansons») на тексты оригинальных французских поэм Р. Рильке, написанные Хиндемитом в 1939 году, можно причислить к периоду творческой зрелости его музыкального стиля. На этом жизненном этапе композитор интенсивно работал в направлении логического обобщения всеобщего и своего собственного опыта сочинения музыки. Двумя годами ранее была опубликована первая часть его теоретико-методического труда «Руководство по композиции» (в оригинале - «Unterweisung im Tonsatz»), а в 1939 году была завершена вторая часть этого масштабного труда.

В связи с этим логично будет предположить, что «Шесть хоров» несут на себе некоторый отпечаток объемной и значительной интеллектуальной работы по осмыслению фундаментальных закономерностей музыкальной речи, уточнению принципов и норм ее органи- 
зации. Это не противоречит тому, что данное произведение достойно особого внимания музыкантов-исполнителей.

Заметим, что творческая личность П. Хиндемита воспринималась идеологами Советского Союза сравнительно благосклонно (особенно после смерти композитора). Это связано с тем, что он в начале своего творческого пути проявлял симпатию к левым идейно-политическим движениям, стремился к революционному обновлению и демократизации музыкального искусства. Имело значение и то, что в фашистской Германии его музыка считалась «культурбольшевистской», «красной», «революционной» [1; 2]. Возможно, эти обстоятельства повлияли на тот удивительный факт, что в 1969 году издательство «Музыка» выпустило большим тиражом цикл «Шесть песен» - произведение весьма далекое от идеалов эстетики социалистического реализма, написанное немецко-американским композитором-модернистом на стихи немецкого поэта-экспрессиониста (партитура была опубликована с русским текстом молодого поэта С. Вольского).

К сожалению, в монографии Т. Левой и О. Леонтьевой этот цикл специально не рассматривается (основное внимание авторы уделили крупным произведениям кантатно-ораториального жанра). Большего внимания данное произведение удостоилось в статье СкребковойФилатовой [5], где приведены некоторые фрагментарные суждения аналитического характера. Наибольшей полнотой освещения формальных и образно-содержательных особенностей цикла «6 chansons» отличается диссертационное исследование П. Кисилева [2]. Заметим, что украинские музыковеды весьма результативно исследуют стиль и технику композиции П. Хиндемита на материале его инструментальных сочинений, оставляя без внимания его произведения для хора. Зарубежных работ на эту тему также очень мало. Нам известно о существовании монографии на немецком языке, написанной А. Рубели, которая посвящена хиндемитовским хорам а capella [7]. К сожалению, познакомиться с этим трудом пока не удалось.

Можно в целом заключить, что хоровое творчество Хиндемита освещено в отечественной и зарубежной музыковедческой литературе очень мало (это особенно заметно на фоне доброй сотни публицистических, критических, исследовательских работ, посвященных другим жанрам и сферам деятельности композитора). Вместе с тем изучение именно хоровой музыки композитора открывает прямой путь к пониманию его индивидуальной стилевой манеры и, далее, к 
обнаружению более универсальных принципов организации тонального устройства и гармонического языка всей музыки XX века. Произведения Хиндемита не менее актуальны для освоения основ современного хорового письма, принципов фактурной и композиционной организации произведений для хора. В этом плане цикл «Шесть песен» представляется произведением, несомненно заслуживающим включения в репертуар хорового класса, а также в курсы специального сольфеджио, хорового дирижирования, чтения хоровых партитур для будущих хормейстеров и пианистов.

Прежде всего, отметим особенности литературной основы цикла - ряда стихотворений Райнера Марии Рильке, написанных на французском языке (поэт был гражданином Австрии, писал стихи преимущественно на немецком языке). Что привлекло композитора в этих текстах? Позволим себе высказать следующее предположение: Рильке - поэт, который был во многом близок художественной натуре Хиндемита (хотя темпераменты обоих и судьбы очень отличались). Оба мастера ненавидели в искусстве пошлость, консерватизм, проявления дурного вкуса и низменных потребностей, нравственную индифферентность. Оба стремились к искреннему самовыражению, к непосредственной экспрессии чувств и мыслей.

Тексты Рильке, выбранные Хиндемитом, отличаются внешней простотой, открытостью, лаконичностью, образной точностью выражения и (что, вероятно, было особенно привлекательным для композитора) отсутствием какой-либо этнической, национальной, религиозной, идеологической, эстетико-философской или иной ограниченности. В 1939 году, когда достигли своего страшного апогея нацистские движения в Германии, Италии и Японии, когда стала очевидной бесчеловечность тоталитарного большевизма, с особой остротой стали восприниматься самые простые и, одновременно, самые высокие общечеловеческие ценности: красота и величие природы, красота человека, радость бытия. Именно эти ценности и представлены в шести внешне скромных и непритязательных поэтических миниатюрах: «Лань», «Лебедь», «Если все проходит», «Весна», «Зимой» «Фруктовый сад».

В тексте Рильке начисто отсутствуют пафос, интеллектуальная претенциозность, острота драматических коллизий, масштабность тематики. Этим свойствам идеально соответствует музыкальный стиль произведения. Не случайно композитор обратился к выразительным средствам смешанного хора a capella. Этот вид хорового ан- 
самбля обладает прекрасными возможностями создания в широком звуковысотном диапазоне многокрасочного, сбалансированного звучания, весьма пластичного в отношении артикуляционных и динамических оттенков.

Еще одна заметная особенность произведения - соблюдение почти на всем протяжении цикла типа аккордово-полифонической фактуры. В этой доминирующей хоровой фактуре одинаково хорошо слышны как горизонтальные элементы (мелодические линии одного или более голосов), так и вертикальные элементы - аккордовые и неаккордовые созвучия. Данное качество фактуры произведения цикла особенно ценно для его включения в академический репертуар подготовки музыкантов-профессионалов.

Благодаря прозрачности и синтетическому устроению фактуры в обсуждаемых хорах Хиндемита с особенной ясностью проступают закономерности гармонического языка, присущего не только стилю самого композитора, но и многим другим стилям музыки XX в.

В чем заключаются эти особенности? На этот вопрос отвечали многие музыковеды-исследователи. Достаточно сослаться на работы Ю. Кона, Г. Метца, Д. Ноймейера, Ю. Холопова, Г. Шуберта, М. Этингера.

Изучение музыкального текста «Шести хоров» позволяет ставить некоторые новые теоретические вопросы относительно тональной системы и гармонических средств музыкального языка Хиндемита. В данной статье мы хотим подчеркнуть лишь те свойства произведения, которые наиболее существенны для учебного процесса, в частности - для формирования представлений студентов о гармонических средствах современной музыки.

Прежде всего обратим внимание на основное качество аккордики Хиндемита, а именно на ее акустическую обоснованность, ее слуховую «естественность». Сознательный и последовательный отказ композитора от той системы европейской функциональной гармонии, которая опирается на терцовые аккорды, привел его к необходимости установления иных слуховых ориентиров для организации интонационного процесса, как «по горизонтали», так и «по вертикали». В системе Хиндемита такими ориентирами стали самые природные для слуха в физическом и физиологическом смыслах соотношения тонов, а именно чистые октавные, квинтовые и квартовые созвучия. В определенном смысле композитор вернул слуховые настройки, присущие музыке, начиная с самых древних времен. Именно эти 
интервалы были, как установилено современной историей музыки и этномузыкологией, первоначальными строевыми регуляторами музыкального интонирования.

Данная строевая ориентация утверждается уже в самой первой музыкальной фразе цикла: «O la biche» (в русском тексте С. Вольского - «Ты прекрасна»). Фраза строится на квинтовом «каркасе» звуков «ля - ми», заполненных диатоническими ступенями лада (звуки «си» и «ре»). Этот начальный звукоряд образует пентахорд с пропущенной третьей ступенью. Такая конструкция позволяет избежать даже малейшего признака традиционного ладотонального построения. В ней нет даже намёка на мажорный или минорный ладовый центр. Вместе с тем данная звуковысотная структура служит, как это легко проверяется практикой музицирования, очень прочным, очень надежным слуховым ориентиром и, одновременно, тематическим элементом для построения всей композиции части. Можно согласиться с П. Кисилевым, заметившим, что «...в интонации вступительной попевки первого хора «Лань» заложен «генетический код» всего цикла, поскольку она состоит из звуков квартаккорда» $[2,15]$.

Следует отметить, что мелодические фразы, очерчивающие в линеарном измерении главные звуковысотные элементы гармонической системы, выступают во всех хорах Хиндемита важнейшим ориентиром слуховой настройки. Такой принцип взаимного проникновения и взаимной детерминации «горизонтальных» и «вертикальных» структур характерен для модально-ладовых систем фольклорного многоголосия, а также для средневековой церковной полифонии. Он стал одним из основных для языка современной музыки (в особенности - для неофольклорного и неоклассического направлений).

Дальнейшее развертывание гармонической последовательности в хоре «Лань» уже не избегает аккордов терцовой структуры, но использует их по-своему, не вполне в соответствии с классической традицией. Полноценные трезвучия в основном виде практически не встречаются. Обычно мы слышим полные и неполные секстаккорды или квартсекстаккорды, чаще всего дополненные каким-либо одним тоном, находящимся в секундовом отношении к тонам акустического кварто-квинтового каркаса. Так, скажем, в следующей фразе начального хора появляются созвучия: «ля - до-диез», «ля - до-диез фа-диез» с дополнениями «соль-диез» и «ре-диез».

Неподготовленному слуху может показаться, что последовательности таких созвучий случайны. Традиционно ориентированный слух 
ищет в этих рядах созвучий привычной логики функциональных отношений. И, не найдя их, теряется, утрачивает ощущение логично устроенного звукового пространства. Однако, если подготовить слух и настроить восприятие соответствующим образом, логика вертикальных элементов и гармонического развития обнаруживается довольно ясно.

Функцию настройки, которая необходима для слухового привыкания и обретения уверенности при вокальном исполнении, должны выполнять, прежде всего, кварто-квинтовые созвучия. Эти структуры в музыкально-языковой системе Хиндемита выполняют роль тоникальной гармонии (или центрального элемента звуковой системы, если пользоваться терминологией Ю. Холопова). Они служат «гравитационными центрами», которые притягивают и регулируют, направляют все мелодическое и аккордовое движение.

«Гармония Хиндемита, - по замечанию Ю. Холопова, - чрезвычайно разнообразная и подвижная в отношении применяемых в ней аккордовых форм, все же нередко обнаруживает предпочтение одного излюбленного комплекса, действующего и по горизонтали и - в особенности - по вертикали. Приобретая разные обличья, смешиваясь с другими элементами, он продолжает оставаться характерно хиндемитовским звучанием. Это пентаккорд квартовой структуры» [3, 212213]. Заметим, что сам композитор называет этот специфический элемент своей гармонической системы «кварт-квинтаккордом» [6, 451].

Стабильно появляющиеся кварто-квинтовые аккорды (пентаккорды) образуют своеобразные кадансы, аналогичные кадансам на основе функциональной терцовой аккордики. К примеру, первое тематическое построение в хоре «Лань» (оно занимает 4 такта и выполняет роль первой части в развитой трехчастной репризной композиции) скреплено силами притяжения мелодических линий к кварте «си - ми», образованной в кадансе крайними голосами: басом и сопрано. Звуки «фа-диез» и «ре» в последнем созвучии темы имеют второстепенное значение, но они все-таки принципиально важны в качестве опор для мелодического интонирования и гармонического звучания. Для того, чтобы корректно озвучить начальное тематическое построение хора (в вокальном исполнении или в звучании фортепиано), необходимо ясно услышать, выразительно и чисто воспроизвести не только экспрессивный контур партии сопрано, но также и нисходящую линию басового голоса, поступенно нисходящую от тона «ля» малой октавы до «си» большой октавы (эта линия образована сомкнутым соединением двух дорийских тетрахордов). 
Существенный признак гармонии Хиндемита, который дестабилизирует классическую слуховую настройку и требует адаптации слуха, - обилие параллельных интервалов и созвучий. В классической гармонии такой вид фактуры строго избегался во имя сохранения самостоятельности мелодических линий и логики гармонических перемен. В гармонической системе Хиндемита параллельные чистые кварты, квинты и октавы встречаются столь же часто, как параллельные терции и сексты в музыкальной фактуре произведений романтического стиля. Появление подобных созвучий можно объяснять как следствие обращения к гетерофонному принципу построения многоголосной фактуры. Но не исключено и обратное: гетерофонная ткань образуется вследствие последовательного колористического и ладообразующего использования аккордов одинаковой структуры, основанных на кварто-квинтовом отношении тонов.

Еще одна особенность гармонии Хиндемита, в определенной степени присущая гармоническому языку большинства представителей музыкального неоклассицизма, - ранжирование аккордовых созвучий по степени их объективной акустической диссонантности. Данный подход вносит в комплекс стабильных созвучий хиндемитовского музыкального языка принцип особой функциональной упорядоченности. В свою очередь, акустическая дифференциация аккордов позволяет композитору подчинить гармонические последовательности четким синтаксическим моделям. Как точно отметил Ю. Холопов: «Для гармонии зрелого стиля Хиндемита типична максимальная сглаженность и законченность выражения, происходящая от тщательной заботы композитора о разрешении наиболее острых диссонансов в менее острые, менее острых - в мягкие, мягких - в консонансы. Это придает гармонии неуловимо старомодный, «неоклассический» отпечаток. Тому же эффекту способствует и свойственная хиндемитовской гармонии плавность в постепенном отходе от тоники и возвращении к ней» [3]. Данный принцип гармонического синтаксиса заметен во всех пьесах цикла «Шесть песен». Например, данной норме подчиняется тонко колорированная гармоническая ткань последней пьесы цикла - «Фруктовый сад».

Итак, мы пришли к следующим выводам:

1. Цикл репрезентирует вполне оформившийся и ясно осознанный в образно-понятийных категориях гармонический язык Пауля Хиндемита. 
2. Этот гармонический язык органично связан, можно даже сказать - порожден новым слышанием, новым интонационно-категориальным осмыслением ладотональной организации музыкальной речи. Эта организация, в свою очередь, глубоко укоренена в музыкальной традиции средневековой монодии, ренессансной многоголосной музыки. Она несет на себе отпечатки интонационного строя крестьянского фольклора и связана с музыкально-поэтическими свойствами жанров эпохи позднего Возрождения и Реформации (мотет, шансон, мадригал, протестантский хорал).

3. Свойства аккордики в хорах цикла обусловлены: а) опорой на кварто-квинтовые строевые отношения, б) организующим доминированием акустически чистых интервалов, в) принципом свободного сочетания диатонических тонов в созвучиях, «естественно» образованных мелодическим движением голосов, г) логикой устройства синтетической аккордово-полифонической фактуры, д) принципом волнообразного нагнетания и разряжения уровня диссонансности созвучий, который служит задаче формирования единиц высшего уровня синтаксической организации музыкальной речи.

4. Методическая целесообразность использования цикла в курсе чтения хоровых партитур объясняется: а) задачей воспитания гармонического слуха, способного к апперцепции гармонической ткани современной хоровой партитуры, б) удобством партитуры (возможностью использования зафиксированной композитором партии клавира на начальном этапе освоения текста).

\section{СПИСОК ЛИТЕРАТУРЫ}

1. Анисимов А. Пауль Хиндемит. Шесть песен на тексты оригинальных французских поэм Р. Рильке. М. : Музыка, 1969. 28 с.

2. Кисилев П. Хоровое творчество Хиндемита: автореф. дис. ... канд. искусствоведения: 17.00.03. Москва, 2008. URL: http://cheloveknauka.com/ horovoe-tvorchestvo-hindemita\#ixzz3toRghtf3

3. Кон Ю., Холопов Ю. О теории Хиндемита. Советская музыка. 1963. № 10.

4. Левая Т., Леонтьева О. Пауль Хиндемит. Жизнь и творчество. М.: Музыка, 1974. 448 с.

5. Скребкова-Филатова М. Об особенностях развития фактуры в камерных хорах П. Хиндемита. Мастера ХХ века. М.: Сов. композитор, 1979. C. 179-209.

6. Этингер М. Гармония в полифонических циклах Хиндемита и Шостаковича. Теоретические проблемы музыки ХХ века / ред.-сост. Ю. Тюлин. М.: Музыка, 1967. Вып. 1. С. 441-471. 
7. Rubeli A. Paul Hindemiths a Cappella-Werke. Frankfurter Studien: Published by B. Schott's Sohne. Mainz, 1975.

\section{REFERENCES}

1. Anisimov, A. (1969) Paul Hindemith. Six Songs on the text of the original French poems by R. Rilke. M.: Music [in Russian].

2. Kisilev, P. (2008). Choral works by Hindemith: Author's thesis.... Extended abstract of candidate's thesis. Moscow, 2008. URL: http://cheloveknauka.com/horovoe-tvorchestvo-hindemita\#ixzz3toRghtf3 [in Russian].

3. Con, Yu., Kholopov, Yu. (1963). On Hindemith's theory. Soviet music, 1963. No.10 [in Russian].

4. Levaya, T., Leontieva, O. (1974). Paul Hindemith. Life and Work. M.: Music [in Russian].

5. Skrebkova-Filatova, M. (1979). On peculiarities of texture development in the chamber choirs by P. Hindemith. Masters of XX century. M.: Sovient composer, 1979. p. 179-209 [in Russian].

6. Ettinger, M. (1967). Harmony in the polyphonic cycles by Hindemith and Shostakovich. Theoretical problems of the music of XX century. M.: Music, Issue 1. p. 441-471 [in Russian].

7. Rubeli, A. (1975). Paul Hindemiths a Cappella-Werke. Frankfurter Studien: Published by B. Schott's Sohne. Mainz [in German].

Стаття надійшла до редакції 22.03.2017

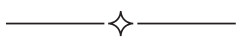

УДК 78.03+78.071.2/78.071.2/.4

Тетяна Олександрівна Федиун

кандидат мистецтвознавства, в.о. доцента кафедри концертмейстерства

Одеської національної музичної

академії імені А. В. Нежданової

tati.fedch@gmail.com

\section{ВПЛИВ ГАСТРОЛЬНО-КОНЦЕРТНОЇ ДІЯЛЬНОСТІ НА СТАНОВЛЕННЯ ФОРТЕПІАННОГО МИСТЕЦТВА ЗАХІДНОУКРАЇНСЬКОГО РЕГІОНУ У ХІХ СТОЛІТТІ}

Мета роботи. Дослідження пов'язане з аналізом гастрольно-концертної діяльності видатних європейських митців та дослідженні їх впливу на формування західноукраїнської фортепіанної традиції, яка завдяки своїм історико-культурним та семантичним особливостям спи- 